\title{
Further Development of the Sextupole Dipole Corrector (MSCB) Magnet for the $\mathrm{LHC}$
}

\author{
Z. Ang, S. Arshad, M. Bajko, L. Bottura, C. Giloux, A. Ijspeert, M. Karppinen, I, Walckiers \\ CERN LHC-Division, Geneva, Switzerland \\ D. Coxill, D. Landgrebe \\ Tesla Engineering Ltd, Storrington, United Kingdom
}

\begin{abstract}
Combined sextupole-dipole corrector magnets (MSCB) will be mounted in each half cell of the new Large Hadron Collider (LHC) being built at CERN. The dipole part, used for particle orbit corrections, will be powered individually and is designed for low current, originally $30 \mathrm{~A}$ but now $55 \Lambda$. The sextupole part, used for chromaticity corrections, is connected via cold busbars in families of 12 or 13 magnets and is powered with $550 \mathrm{~A}$. Several versions of this corrector magnet were tested as model magnets in order to develop the final design for the series. In the first design the coils are nested, with the dipole coil wound around the sextupule coil to ohtain as short a magnet as possible, accepting the slight cross-talk between the coils due to persistent currents, and increased saturation effects. The design has evolved and an alternative design, in which the dipole and sextupole coils are separated, is now favored. 'lests at $4.5 \mathrm{~K}$ and at $1.9 \mathrm{~K}$ were conducted to determine the training behavior, the ficld quality, and the cross-talk between the windings. This paper discusses the results for the different configurations.
\end{abstract}

\section{INERODUCTION}

The LIIC Short Straight Sections (SSS) [1] will be equipped with 1260 num long combined dipole and sextupole corrector magnet assemblies, MSCB [2]. The dipole and sextupole magnets of the two LHC rings are mounted in pairs in a common support structure and housed in the same cold mass and cryostat as of the Main Quadrupoles (MQ) [3]. The sextupole is used to correct the natural chromaticity produced by the focussing elements. Each dipole pair includes a horizontal orbit cortection tor one aperture and a vertical orbit correction for the other.

Two complete MSCB assemblies with the sextupole coils nested inside the dipole coils have been designed by CERN and built in industry, and will be installed in the $3 \mathrm{rd}$ and 4 th LHC prototype Shott Straight Section (SSS). The magnet nssemblies were first mounted in a dedicated single aperture yoke and trained at $4.3 \mathrm{~K}$ by the magnet manufacturer before being integrated into a common yoke structure. To study an alternative of separate magnets, one $0.69 \mathrm{~m}$ long sextupole and one $0.75 \mathrm{~m}$ long dipole were built in industry. Both nested MSCB models and the separate dipole-sextupole units were tested at CERN including magnet training and magnetic measurements at $4.3 \mathrm{~K}$ and $1.9 \mathrm{~K}$. The main design features and the results of the cold tests ate discussed below

Manuscript received 26 September, 1999.

\section{MAGNETIC DESIGN}

The main parameters of the two nested versions of the MSCB magnets are presented in Table I logether with those of the separated dipole and sextmpole models. The dipole of the first MSCB was designed to produce a $1.5 \mathrm{~T}$ field will: the nominal current of $30 \mathrm{~A}$ and the sextupole to create a gradient of $1500 \mathrm{~T} / \mathrm{m} 2$. The coils of the second nested MSCB model were re-optimized to reduce the quench voltages in the dipole and to operate the sextupole with a $66 \%$ margin to quench at $1.9 \mathrm{~K}$. The number of radial winding layers of the sextupole coils was reduced from 8 to 4 and the nominal current was increased from $230 \mathrm{~A}$ to $394 \mathrm{~A}$. The dipole coils were designed to produce a $16 \%$ higher field of $1.8 \mathrm{~T}$ at the nominal cursent of $50 \mathrm{~A}$.

The separate version of the sextupole had the same coil cross-section as the sextupole of the first nested MSCB. The nominal current was increased to $560 \wedge$ to produce the required field integral with the reduced length. The separate dipole was made stronger to provide a 3 l" field at a current of $55 \mathrm{~A}$.

TABLE I

Main Parameters of Msce Dipole Sextujole Cokjector Molyil.s

\begin{tabular}{|c|c|c|c|c|c|}
\hline & $\begin{array}{l}\text { Nested } \\
\text { (3) SSS }\end{array}$ & $\begin{array}{l}\text { Design } \\
4^{\text {UL }} \text { SSS) }\end{array}$ & Sopara & e Designt & \\
\hline & Dipole & Sextupole & Djpolc & Sextupole & \\
\hline MAGNETIC & & & & & \\
\hline $\begin{array}{l}\text { Nomitnal field } \\
(\mathrm{r}=17 \mathrm{~mm})\end{array}$ & $1.5 / 1.8$ & $0.43 / 0.43$ & 3.0 & 1.23 & 'l' \\
\hline Magnetie leugth & 1.03 & 1.1 & 0.547 & 0.525 & $\mathrm{~m}$ \\
\hline Peak field in coil & $2.7 / 3.0$ & $3.0 / 3.3$ & 3.4 & 4.0 & $\mathrm{~T}$ \\
\hline GEOMETRIC & & & & & \\
\hline Dvorall length & 1. & & 0.745 & 0.693 & $\mathrm{~m}$ \\
\hline Coil length & 1. & 15 & 0.655 & 0.585 & mi \\
\hline Coil lD & $80 / 70$ & $56 / 56$ & 56.4 & 56 & trinn \\
\hline Coil OD & $96 / 87$ & $76 / 66$ & 79.5 & 66 & m \\
\hline Yoke ID & & & & 5.5 & mıiı \\
\hline Yoke OD & 452 & $4 \$ 2$ & & 74 & $\mathrm{~mm}$ \\
\hline ELEC'I'RIC & & & & & \\
\hline Nominal curtent & $30 / 50$ & $230 / 394$ & 55 & 560 & A \\
\hline Tutris/coil & $2240 / 1530$ & $112 / 52$ & 1775 & 112 & \\
\hline Stored energy & $7.0 / 8.2$ & 1.919 & 7.4 & 6.6 & $\mathrm{~kJ}$ \\
\hline Setf inductarice & $21 / 6.6$ & $0.072 / 0.035$ & 4.89 & 0.042 & $\mathrm{H}$ \\
\hline CONDUCTOR & & & & & \\
\hline Cross section & $0.11 / 0.14$ & $0.91 / 0.91$ & 0.14 & 091 & $\mathrm{~mm}^{2}$ \\
\hline $\begin{array}{l}\text { Ctoss } \\
\text { section(metal) }\end{array}$ & $0.08 / 0.11$ & $0.69 / 0.69$ & 0.11 & 0.69 & $\mathrm{~m}^{2}$ \\
\hline Cu/Sc matio & $4 / 4.2$ & 1.71 .7 & 4.2 & 1.7 & \\
\hline Filament dianı. & $7 / 27$ & $7 / 7$ & 27 & 7 & $\mu m$ \\
\hline Margin to quonch & $59 / 49$ & $77 / 66$ & 39 & 40 & $\%$ \\
\hline
\end{tabular}




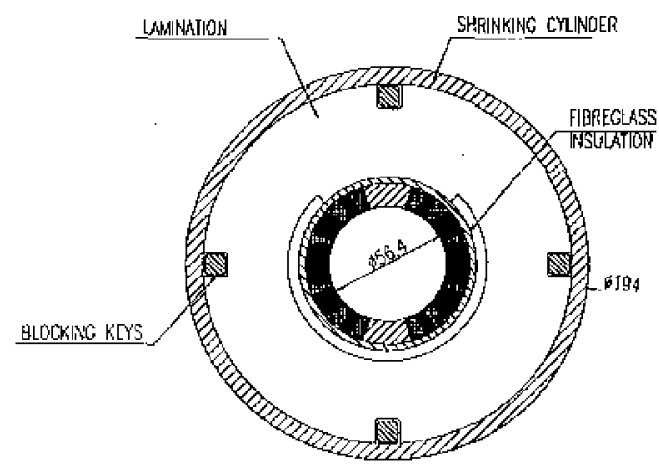

lig. 1. Cross-section of the separate dipole mode!.

\section{MECHANICAL DESIGN AND FabRICATION}

The sextupole coils are wound around a copper central post using a single enamel insulated, rectangular crosssection superconducting wire. The winding is subdivided at the ends into seven blocks to house the radial and axial transitions, so-called "joggles", between the turns. For the first model the 4-block dipole coils are wound with 21 round superconducting wires, pre-assembled as a flat cable. The flat cable for the second MSCB model was made of 18 wites with a metal section diameter of $0.375 \mathrm{~mm}$ instead of the $0.31 \mathrm{~mm}$ used for the $30 \mathrm{~A}$ design. The coils of the separated version are wound using a cable that is composed of 25 wires. All dipole and sextupole coils are vacuum impregnated.

The six sextupole coils are mounted on an assembly mandrel, aligned with dowel pins and then wrapped with dry fiberglass cloth prior to impregnation and curing. The onter diameter is then turned to the required dimension. In the nested version the dipole coils are then mounted around the sextupole coils and wrapped with fibreglass before impregnating the whole assembly in vacuum. The separate dipole is assembled like the sextupole.

The wires of the flat cable in each dipole coil are comected in series by soldering the twisted ends and these connections ate then soldered onto a printed circuit board for mechanical fastening. The series connections of the sextupole coils are made by soldering in tight-fitting grooves in copper backing pieces.

The pre-stress in the nested coils is given by fitting an aluminum shrinking cylinder, subdivided into $100 \mathrm{~mm}$ long segments, around the coil assembly with a radial interference of $0.10 \mathrm{~mm}$. In the case of the separate dipole and sextupole models the pre-compression is applied to the coils by shrink fitting an aluminum cylinder over the eccentric steel laminations [4] that makes up the yoke, as shown in Fig. 1. In this case each lamination is designed to support the coil assembly in one azimuthal direction only and the laminations were assembled in pairs such that each pair compresses the coil assembly from opposite sides. By sequentially stacking these pairs such that the subsequent pair is turned by $90^{\circ}$ with respect to the previous one the coil assembly is effectively supported. Four keys were introduced to limit the coil

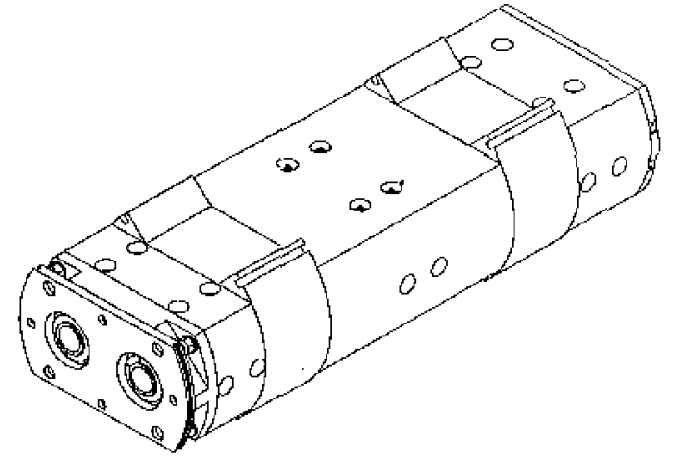

Fig, 2. MSCB assembly for the $3^{\text {rl }}$ SSS

compression in cold conditions. The clearance between these keys and the laminations at room temperature is chosen such that the inward movement of each lamination pait is blocked at a pre-defined temperature.

The yoke structure of the MSCB for the SSS3 illustrated in Fig. 2 was made of $1 \mathrm{~mm}$ silicon steel laminations glued together in a precise stacking lixture and secured with four tie-rods. Three sets of keys were located in each aperture and after inserting the magnet assemblies with pre-machined keyways on their shrinking cylinders the keys were locked in with screws. The yoke structure of the second pair for the SSS4 is made in the same way as the Main Quadrupole, i.e. the laminations are assembled with elastic pins and aligned with the external keys that locate the MSCB assembly with respect to the Inertia Tube $[1]$ of the SSS.

\section{A. Training}

\section{TEST Results}

The training results for the dipole and sextupole in one aperture of the 2nd nested model, and for the sepatated sextupole and dipole models are shown in Fig. 3 and 4 respectively. In the former case the tests included individual and combined powering of the nested coils. The fuli working space is accessible in both models after training. The nested design showed only slight improvement when cooled to $1.9 \mathrm{~K}$. No retraining was observed after thermal cycling.

In the separated coil version the slow initial training was caused by too low a pre-stress. After re-fitting the shrinking cylinder with a higher interference only two quenches oceutred below the operating current and both the sextupole and the dipole trained up to their short sample limits. The high quench voltages, up to $760 \mathrm{~V}$ observed for the 1 st nested model, were reduced to $430 \mathrm{~V}$ for the 2 nd one.

The hot-spot temperature was below $140 \mathrm{~K}$ for all the magnets. An example is given in Fig. 5, showing individual voltage tap measurements along one pole of the dipole coil. The maximum voltage corresponds to the peak of the sum of the individual measurements. The Fig. 5 also shows propagation of the quench in the coil over a period of $\sim 40 \mathrm{~ms}$, which is consistent with transverse thermal conduction through the coil. 


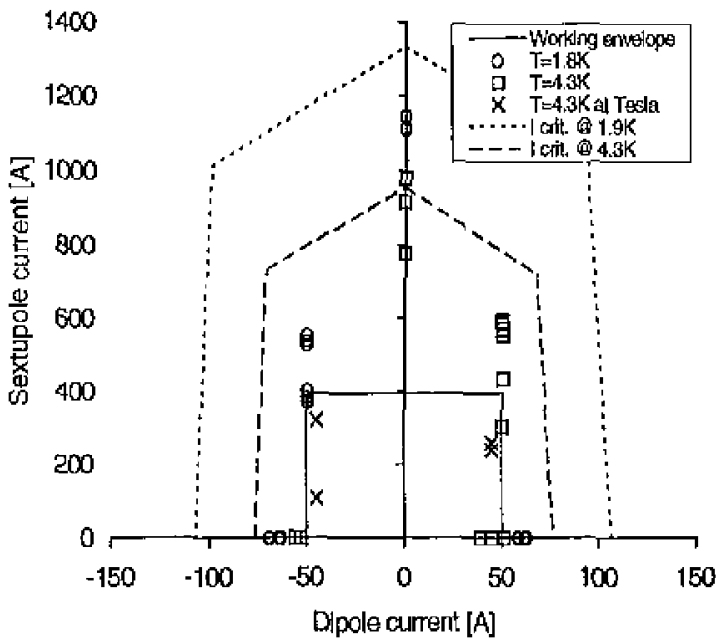

Fig. 3. Individual and combibed trining quenches of the sexulpole and dipole windings in nne of the apettures of the second nested MSCB design

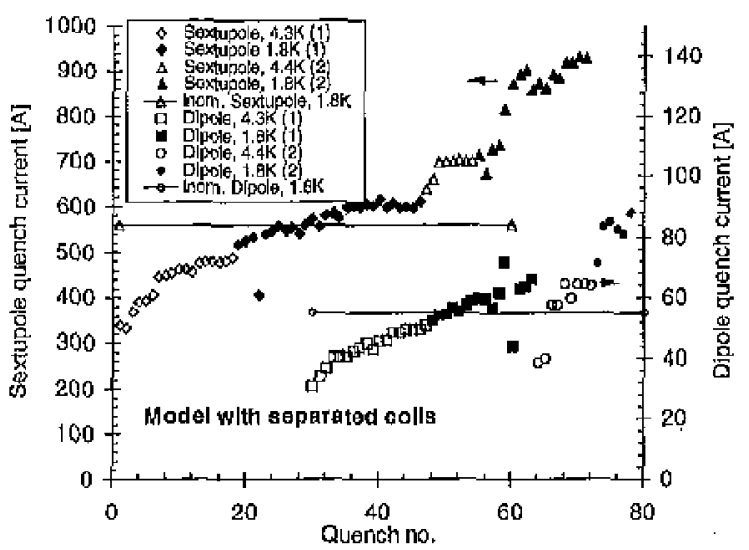

Fig. 4. Training of the dipole and sextupole of the third model with separated coils. The labels (1) and (2) correspons to tatining before and afler increasing the pre-stress respectively.

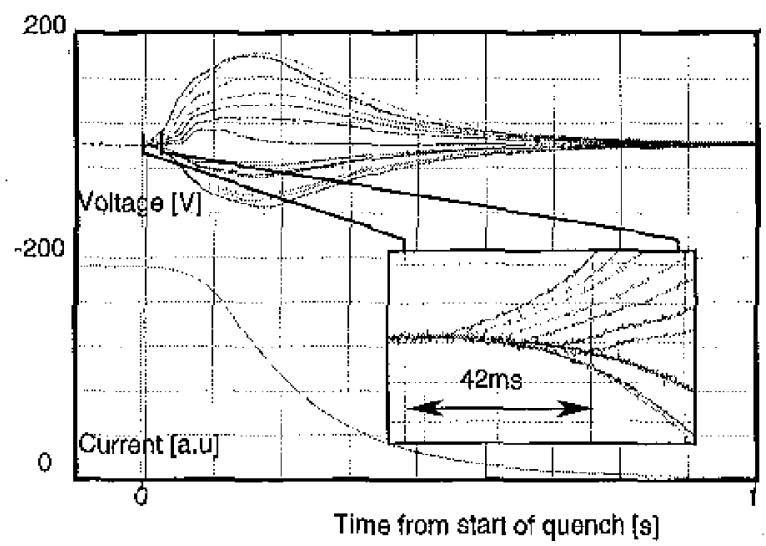

Fig. 5. Voltages across indiwidual layers and eurrent during a quench in a dipole of the first nested design. The inlay shows propagation of the quench actoss bic layers.

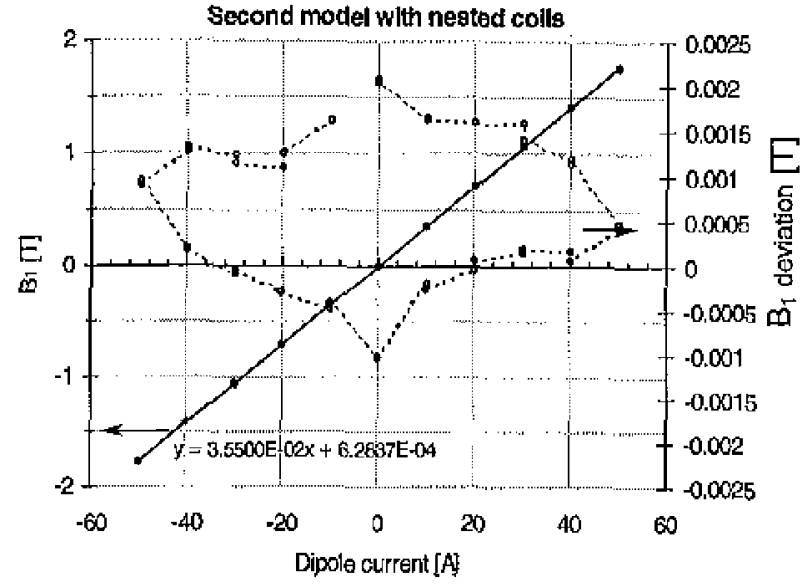

Third model with separated colls

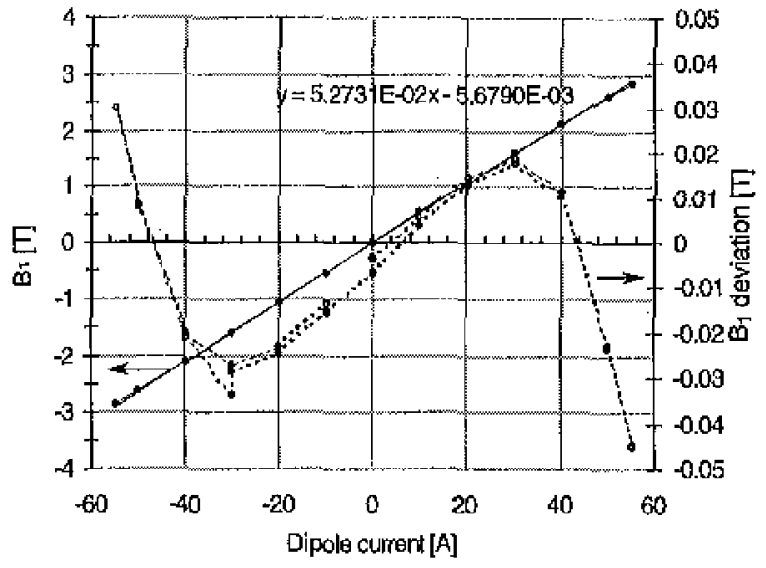

Fig. 6. Mcasured loodlines and hysteresis in the second nesterl coil and the separated coil models.

\section{B.Magnetic Measurements}

The dipole loadlines and hysteresis loops for the 2nd nested model and the model with separated coils are shown in Fig. 6. The deviation is calculated as the difference between the loadline and a linear lit to the loadline, The shorter length of the coil in the model with separated coils implies a higher nominal ficld ( $3 \mathrm{~T}$ compared with $1.8 \mathrm{~T}$ in the 2nd nested model), which is evident in the loadline. A consequence of this is the much higher degree of saturation in this magnet. Similar features are seen in the sextupole windings.

The levels of hysteresis at zoro current for the dipoles and sextupoles of the three models are compared in Fig. 7. A signilicantly lower lovel is found for both the dipole and in particular the sextupole in the scparated coil model, for most harmonics in the range 1 to 9 .

[iig. 8 shows the hamonic content of the dipole and sextupole in the model with separated coils. Values are given at beam injection $(0.2 \mathrm{Tm}$ for the dipole and $0.012 \mathrm{Tm}$ for the sextupole) and at beam collision (1.65 Tm for the dipole and $0.48 \mathrm{Tm}$ for the sextupole). Absolute levels of both normal and skew components ate shown. 

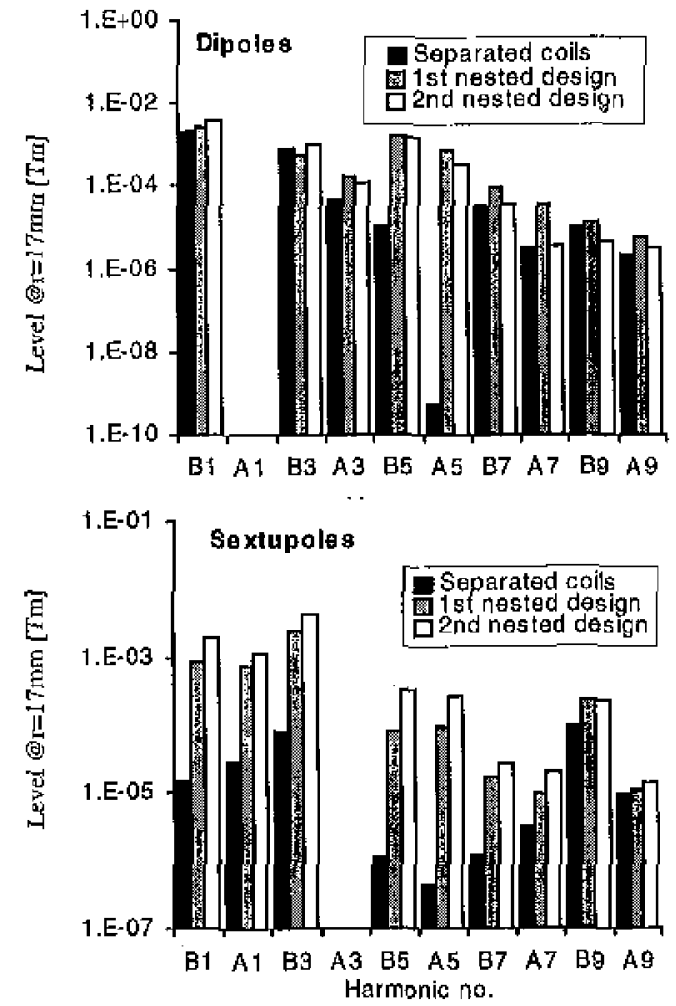

Fig. 7. Compntison of the maximum hysteresis seon in the dipole and sextupole coils of the three MSCB models at zero current. Bo and An are normal and skew components respectively integrated over length.

An important requirement for the operation of the accelerator is that the ficld patterns generated by energising any combination of coils should correspond closely to the linear superposition of their individual loadlines. It might be expected that in a nested coil system internction between the individual coils could complicate the compound ficld pattern giving rise to increased non-linearity. In practice this effect is found to be small. In the 2 nd nested model the composito ficld deviates from the linear superposition of the loadlines by a maximum of $\sim 1 \mathrm{mT}$ for the dipole component and $\sim 2$ $\mathrm{m}$ 'T for the soxtupole component. All other harmonics deviate by less than $0.5 \mathrm{mT}$. In the model with separated coils this effect was below $1 \mathrm{mT}$ for both the dipole and sextupole components and below $0.5-\mathrm{mT}$ for other components, Thercfore, from this point of view, the nested models do not appear to be very different from the arrangement with separated coils.

The nested models tested were built with twin apertures, and in the 2nd nested version the cross-talk between apertures is found to be at a level of $0.5 \mathrm{mT}$ for the dipole component and bolow $0.1 \mathrm{mT}$ for other components.

\section{CONCLUSIONS}

The experience with several nested magnet models has shown some magnetic and mechanical coupling between the
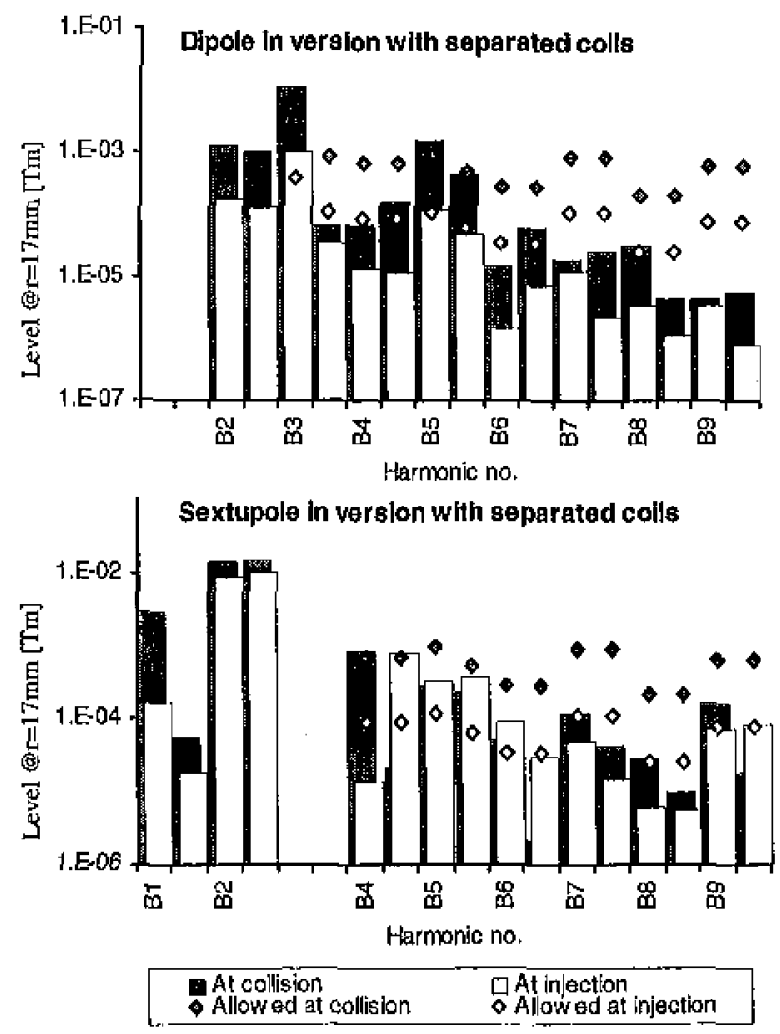

Fig. 8. Measured harmonic content of the dipole and sextupole for the model with scparated coils. For each hannonic both the nomal and skew comporents are shown and compared with the estimated tolerances [5]

different coils, Short separated models with increased field were successfully built and proven to be a valid alternative to the nested design. This version is considerably simpler to fabricate and the modular arrangement provides more flexibility for assembly of the final units in the machine. On this basis it is the preforred design for the LHC.

\section{REFERENCES}

[1] J-M. Riffet, M. Poyrot, P, Rohmig, T, Tortschantoff , P, Vedrine, "Status of the Cold Mass of the Short Straight Section for the LHC", CERN LHC Project Report 182, May 1998.

[2] A. ljspeert, R. Perin, L. Walckiers, E. Baynharn, P. Clee, R. Coombs, M. Begg, D. Landgrebe, "Test Results of the combined sextupoledipole corrector magnet for LHC", Applied superconductivity Conference, Clugago, August 1992

[3] N, Siegel, T, Tortschanoff, J-M Rifflet, P. Giovannoni,F. Le Coz, C. Lytaud, J. Perot, P. Vedrine, "Status of the fabrication and test of the prototype LHC Jattice quadrupote magnets", 13th International Conference on Magnet Technology, Victoria, BC, Canada, Sep 1993.

[4] A, Ijspeert, J. Salminen, "Supereonducting Coil Compression by Seissor Latnitnations", EPAC, Sitges, Spain, June 1996.

[5] A. Verdier, "Tolerance on the Muttipole Components in the Closed Orbit Correctors", LHC Project Note 51, CERN, Geneva, Switzerland, August 1996. 